\title{
Comportamento de vinte cultivares de feijão-de-praia (Vigna unguiculata (L.) Walp) em terra firme do Estado do Amazonas, durante o ano de 1977
}

\author{
Kaoru Vuyama $(*)$
}

\begin{abstract}
Resumo
Vinte cultivares de feijão-da-praia, 19 cultivares introduzidas do IITA e uma cultivar local, tiveram seus desempenios estudados, em solo de terra firme, localidade de Iranduba-Manaus, no ano de 1977. O experimento indicou que as 19 cultivares introduzidas apresentaram resultados superiores em relação à melhor cultivar local "INPA-III". As cinco cultivares mais produtivas foram VITA-3, TVx1193-059D, VITA-1, VITA-4 e TVx 456-01F, com 2128, 2055, 2038, 1957 e $1850 \mathrm{~kg} / \mathrm{ha}$ de grâos, respectivamente. A cultivar VITA-3 mostrou meIhor desempenho para as caracteristicas estudadas, tais como: indice de debulha de $62 \%$, alta produção de grăos, alto peso de sementes, plantas altas, ciclo biológico médio e número de vagens por planta razoável. Houve pouca incidência de insetos e doenças, atribuindo-se tal fato à baixa precipitação, durante a condução do experimento, sendo que a praga mais freqüente foi a vaquinha (Diabrotica spp) e algumas plantas isoladas apresentaram podridão branca da haste (Sclerotinia scleroticrum) e virus do mosaico (CPMV). Para recomendação final de cultivares introduzidas, devem ser conduzicos ensaios regionais sobre épocas de semeadura e sua influência em incidência de pragas e doenças.
\end{abstract}

\section{INTRODUÇẢO}

O feijão-de-praia (Vigna unguiculata (L.) Walp) é uma das mais importantes fontes de alimentos básicos com alto teor nutritivo para o povo amazonense, por ser de custo relativamente baixo e de fácil cultivo. Por outro lado, possui una grande adaptabilidade ao meio ambiente amazônico, enquanto que, o feijão comum (Phaseolus vulgaris L.) não se adapta bem na região. Rego (1970), fazendo comparação química de Phaseolus e Vigna, obteve $27,2 \%$ a $27,1 \%$ de proteina do Phaseolus e $24,8 \%$ a $22,8 \%$ do Vigna. Em outro estudo (Rego, 1970) utilizando duas cultivares de Vigna "Quarenta vagens" e "Barba de Guiné" encontroli cerca de 31 e $32 \%$ de proteína, respectivamente. Já Gogfrey-Sam-Aggrey et al.
(1976) encontraram no Vigna toclos os aminoácidos essenciais para o homem.

Rahman (1978) estudou, na várzea do rio Solimões, o comportamento de 19 cultivares de feijão-ce-praia, introduzidas do IITA (Instituto Internacional de Agricultura Tropical) na Nigéria, e uma cultivar local, obtendo resultados muito anımadores. A maioria das cultivares introduzidas foi superior em produtividade à cultiver local, como TVu1630 e TVu2616 com 853 e $847 \mathrm{~kg} / \mathrm{ha}$ de grãos, respectivamente, enquanto que a cultivar local "INPA-III" produziu apenas $167 \mathrm{~kg} / \mathrm{ha}$. Acrescenta o autor que essa baixa produtividade deve-se ao atraso na semeadura fazendo com que a cultura ficasse exposta à elevada pluviosidade, durante seú desenvolvimento, e a alta incidência de doença.

$O$ presente ensaio tem como objetivo verificar o comportamento de 20 cultivares de feijão-de-praia em terra firme, e selecionar as melhores, que servirão como fonte de germoplasma para o programa de melhoramento desta leguminosa na Amazônia.

\section{MATiziAL E MÉTODOS}

O experimento foi conduzido em Vila de Iranduba, Município de Manaus, num solo Podzólico, desmatado há 10 anos. A capoeira existente foi queimada e o solo destocado, arado e gradeado. Aplicaram-se $2 \mathrm{t}$ de calcário para correção de solo e $32 \mathrm{~kg}$ de N. $35 \mathrm{~kg}$ de $\mathrm{K}_{2} \mathrm{O}$ e $60 \mathrm{~kg}$ de $\mathrm{P}_{2} \mathrm{O}_{5}$ por hectare. A semeadura fo; feita no dia $27 / 07 / 1977$.

O delineamento utilizado foi de blocos ao acaso com 4 repetições. A parcela experimental foi constituída de 4 linhas de $4 \mathrm{~m}$ de comprimento espaçadas de $0,75 \mathrm{~m}$, com duas plantas por cova espaçadas de $0,20 \mathrm{~m}$. Considerou-se parcela útil as duas linhas centrais.

(") - Instituto Nacional de Pesquisas da Amazônia, Manaus. 
A semeadura, colheita e debulha foram realizadas manualmente. Durante a condução do experimento, constataram-se alguns ataques de lagarta rosca (Agrotis ipsilon) e elasmo (Elasmopalpus lignoselus) no início da cultura e de vaquinhas (Diabrotica spp) em quase todo o ciclo. As doenças constatadas foram podridăo branca da haste (Sclerotinia sclerotiorum) e virus do mosaico (CPMV) .

As cuitivares utilizadas neste experimentc foram: VITA-1 (TVu201-1D), VITA-4 (TVu1977. OD), VITA-5 (TVu4557), TV $\times 30-1 \mathrm{G}, \mathrm{TV} \times 33-1 \mathrm{G}$, TVx1193-059D, TVx1836-9E, TVx1936-429E, TVx 2551, VITA-3 (TVu1190), TVu662, TVu1502-1G, TVx3-5G, TVx66-2H, TVx456-01F, TVx1836-348E, TVx1836-409E, TVx1836-440E, TVx1836-473E e INPA-III (cultivar local).

Foram coletados dados sobre: produção de grãos, "stand" final das plantas; data da floração, data do aparecimento da $1^{\text {a }}$ vagem madura e data da maturação, expressas em dias após a germinação; altura final das plantas; produção de vagens; número de vagens por planta e peso de 100 sementes.

Os dados foram analizados no Setor de Serviços de Processamento de Dados do INPA. utilizando o Programa ANOVAR (Análise de Variância Fatorial Ortogonal Hierárquica) comı teste F. com 05 de probabilidade e para correlação ao nivel de .05 e .01 de probabilidade.

Na Figura I, encontram-se os dados sobre a precipitação e evapotranspiração durante o período de julho a outubro de 1977, sendo que a precipitação total recebida durante o cultivo foi de $345 \mathrm{~mm}$ (Ribeiro, 1977). No período de deficiência de umidade no solo foi utilizada a irrigação por aspersão, bombeado-se a água cio rio Solimōes.

\section{RESULTADOS E DISCUSSÃO}

No Quadro I, encontram-se os resultados das características agronômicas estudadas nas 20 cultivares: no Quadro II as análises de variância e teste $F$, e no Quadro III as correlaçōes .

Todas as cultivares introduzidas produziram mais do que a cultivar local, sendo as cinco cultivares com produção acima de 1800 $\mathrm{kg} / \mathrm{ha}$ de grãos foram as seguintes: VITA-3.

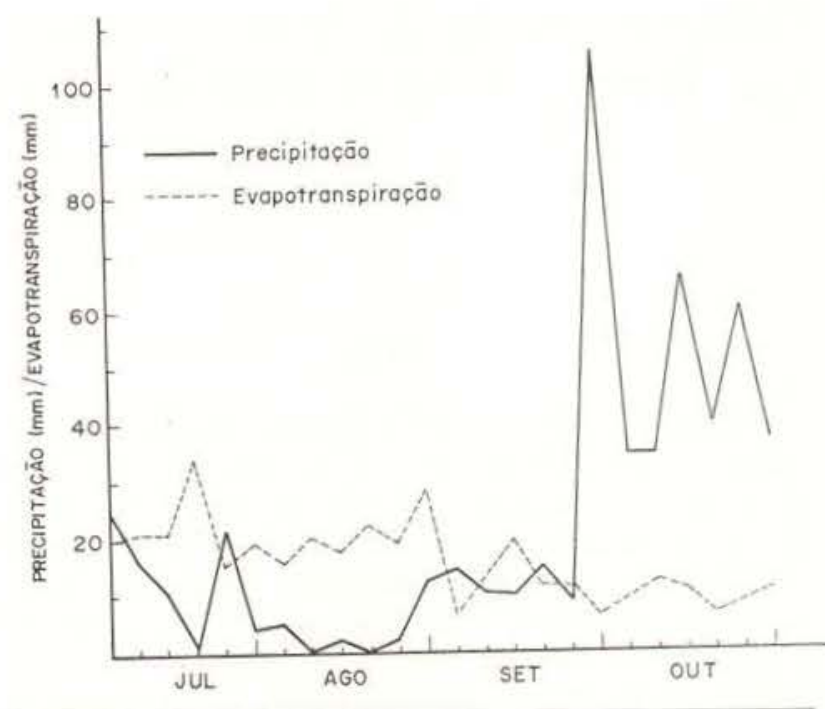

FIG. 1 - Dados sobre precipitação e evapotranspiração, durante o período de julho a outubro de 1977, obti. da na estação meteorológica da Reserva Ducke (Riteiro, 1977).

TVx1193-059D, VITA-1, VITA-4 e TVx456-01F com produçōes de 2127,$47 ; 2054,70 ; 2038,20 ; 1956$, 87 e 1849,67 kg/ha de grãos, respectivamente. Em trabalho realizado por Rahman (1978), na várzea do rio Solimões, as cultivares VITA-3 (TVu1190), VITA-1 (TVu201) e VITA-4 (TVu1977) produziram apenas 314,235 e $77 \mathrm{~kg} / \mathrm{ha}$, res pectivamente. Esta diferença de produtividade foi causada, principalmente, pela época de semeadura inadequada. Conseqüentemente, as condições climáticas da várzea foram desfavoráveis à cultura de feijão-de-praia, dada a alta pluviosidade e elevada incidência de pragas e doenças.

As cultivares VITA-3 e VITA-1 são as mais importantes cultivares desenvolvidas pelo IITA (Albrecht, 1975), por serem tolerantes à cigarrinha (Empoasca dolichi) e trips da folha (Cericothrips occiptalis). Sã̃o também resistentes ou imunes à antracnose (Colletotrichum lindermutianum), pústula bacteriana (Xanthomonas $\mathrm{sp}$ ), mancha foliar (Cercospora canescens e C. cruenta), ferrugem (Uromyces vignae) e algumas raças de vírus do mosaico (CPMV) na região de Ibadan. Ainda, os resultados preliminares da cultivar VITA-3 no Brasil (Albracht, 1975) mostrou uma resistência a duas raças do CPMV, e consta também ser uma cultivar resistente ao nematóide Meloidodyne incognita. 
QUADRO I-Dados de produçăo de grãos, em kg/ha; número de plantas colhidas; floração a $50 \%$, aparecimento da 1. a vagem madura e maturação a $95 \%$, expressos em dias após a germinaçăo; altura da planta, em centímetros (média de 10 plantas); produção de vagem, em $\mathrm{kg} / \mathrm{ha}$; número de vagens por plan. ta (média de 10 plantas) e peso de 100 sementes, expressos em gramas, obtidos no experimento preliminar de 20 cultivares de feijăo Vigna em Terra Firme do Amazonas - 1977.

\begin{tabular}{|c|c|c|c|c|c|c|c|c|c|}
\hline Cultivar & $\begin{array}{l}\text { Produção de } \\
\text { grãos (kg/ha) }\end{array}$ & $\begin{array}{l}\text { N. } \text { de plantas } \\
\text { colhidas }\end{array}$ & $\begin{array}{c}\text { Floração } \\
(50 \%)\end{array}$ & $\begin{array}{c}\text { Aparecimento } \\
\text { da 1.a vagem } \\
\text { madura }\end{array}$ & $\begin{array}{c}\text { Maturação } \\
\text { \{95\%) }\end{array}$ & $\begin{array}{c}\text { Altura da } \\
\text { planta }(\mathrm{cm})\end{array}$ & $\begin{array}{l}\text { Produção } \\
\text { de vagem } \\
\text { (kg/ha) }\end{array}$ & $\begin{array}{c}\text { No de vagens } \\
\text { por } \\
\text { planta }\end{array}$ & $\begin{array}{l}\text { Peso de } 100 \\
\text { sementes }(\mathrm{g})\end{array}$ \\
\hline VITA-3 & 2127,95 & 36,25 & 34,50 & 52,50 & 64,25 & 123.22 & 3441,02 & 27,02 & 21,87 \\
\hline TVx1193-059D & 2054,70 & 32.50 & 35,00 & 55,75 & 57.50 & 47,88 & 3589,19 & 30,35 & 15,12 \\
\hline VITA-1 & 2038,30 & 35,25 & 35,00 & 59,00 & 65,00 & 95,72 & 3533,53 & 27,32 & 17,00 \\
\hline VITA-4 & 1956,87 & 25,60 & 35,00 & 54,00 & 62,50 & 81,60 & 3205,65 & 45,02 & 12,30 \\
\hline TV $\times 456-01 \mathrm{~F}$ & 1849,67 & 38,25 & 37,50 & 56,75 & 77,75 & 90,75 & 3157,49 & 37,35 & 16,25 \\
\hline TVu-662 & 1595,42 & 29,50 & 34,75 & 52,25 & 58,25 & 87,02 & 2833,95 & 28,28 & 12,75 \\
\hline TVx1836-429E & 1580,20 & 34,50 & 35,50 & 50,75 & 67,25 & 63.60 & 2797,49 & 37,18 & 15,50 \\
\hline TVx-30-1G & 1548,70 & 21,00 & 34,50 & 52,00 & 65,25 & 82.20 & 3186,82 & 37.98 & 16,00 \\
\hline TVx-1836-9E & 1524,33 & 26,25 & 34,50 & 49,50 & 59,25 & 36,55 & 2439,57 & 38,60 & 15,58 \\
\hline TVx66-2H & 1503,37 & 31,75 & 35,00 & 54,75 & 62,65 & 73.78 & 2507,61 & 33,70 & 13,50 \\
\hline TVx1836-109E & 1464,13 & 30,50 & 32,75 & 51,50 & 53,50 & 59,45 & 2189,99 & 36,88 & 10,45 \\
\hline TVx2551 & 1431,54 & 30.00 & 35,25 & 51,00 & 59,75 & 8112 & 2667,70 & 39,22 & $\div 6,22$ \\
\hline VITA-5 & 1392,49 & 34,00 & 35,00 & 50,75 & 61,50 & 101,67 & 2813,11 & 28,70 & $! 3,38$ \\
\hline TVx1836-473E & 1326,54 & 31,75 & 32,00 & 44,50 & 52.00 & 43,60 & 2481,99 & 23,55 & 15,78 \\
\hline TVu-1502-1C & 1310,24 & 32,00 & 34,75 & 49,50 & 55,25 & 69,59 & 2395,82 & 29,15 & 11,78 \\
\hline TVx-3-5G & 1263,12 & 34,25 & 35,00 & 53,50 & 63,75 & 69,90 & 2422,70 & 49,42 & 11.10 \\
\hline TVx-1836-348E & 1189,25 & 26,75 & 34,00 & 45,75 & 55.50 & 42,98 & 1936,28 & 31,45 & 14,52 \\
\hline$T V \times-33-1 G$ & 1110,37 & 17,50 & 36,75 & 57,50 & 71,75 & 90,40 & 4258,31 & 3788 & 13,18 \\
\hline INPA-III & 656,37 & 34,50 & 35,75 & 60,00 & 69,00 & 131,97 & 1465,41 & 15,65 & 19,42 \\
\hline C.V. $(\%)$ & 13,01 & 10.13 & 1,78 & 5.14 & 4,89 & 14.57 & 20.55 & 14,73 & 4,98 \\
\hline DMS & 1038,16 & 16,06 & 3,26 & 13,90 & 15,97 & 58,44 & - & 25,87 & 3,91 \\
\hline
\end{tabular}

హ) 
QUADRO II - Resuitacios da análise da variância para cada variável

\begin{tabular}{|c|c|c|c|c|c|c|c|c|c|c|}
\hline $\begin{array}{c}\text { Nome da } \\
\text { variável }\end{array}$ & $\begin{array}{l}\text { Graus de } \\
\text { liberdade }\end{array}$ & $\begin{array}{l}\text { Produçäo } \\
\text { de grãos } \\
\text { (kg/ha) }\end{array}$ & $\begin{array}{l}\text { N.॰ de } \\
\text { plantas } \\
\text { colhidas }\end{array}$ & $\begin{array}{c}\text { Floração } \\
(50 \%)\end{array}$ & $\begin{array}{l}\text { Aparecimento } \\
\text { da 1.a vagem } \\
\text { madura }\end{array}$ & $\begin{array}{c}\text { Maturação } \\
(95 \%)\end{array}$ & $\begin{array}{c}\text { Altura da } \\
\text { planta }(\mathrm{cm})\end{array}$ & $\begin{array}{c}\text { Produção } \\
\text { com vagem } \\
\text { (kg/ha) }\end{array}$ & $\begin{array}{l}\text { N.॰ de } \\
\text { vagens por } \\
\text { planta }\end{array}$ & $\begin{array}{l}\text { Peso de } 100 \\
\text { sementes (g) }\end{array}$ \\
\hline Repetição (SO) & 3 & $5092 \times 10^{3}$ & 1165,00 & 5,73 & 257,80 & 165,10 & $1.902,00$ & $2794 \times 10^{4}$ & 2023 & 7,03 \\
\hline Cultivar (SQ) & 19 & $9758 \times 10^{3}$ & 2339,00 & 106,20 & 1215,00 & 3033,00 & $50.370,00$ & $3113 \times 10^{4}$ & 4421 & 586,50 \\
\hline Erro (SQ) & 57 & $8888 \times 10^{3}$ & 2137,00 & 87,51 & 1662,00 & 2104,00 & $28.160,00$ & $7498 \times 10^{4}$ & 5518 & 126,10 \\
\hline Total (SO) & 79 & $2374 \times 10^{4}$ & 5632,00 & 199,50 & 3136,00 & 5302,00 & 80.430 .00 & $1341 \times 10^{5}$ & 11960 & 719,70 \\
\hline Valor de $F$ & - & $33,29^{\circ} \cdot$ & $3,30^{* *}$ & $3,64^{\circ \bullet}$ & $2,19^{*}$ & $4,32^{\circ *}$ & $5,37^{*}$ & $1,25 \mathrm{~ns}$ & $2,40^{*}$ & $3,95^{* *}$ \\
\hline
\end{tabular}




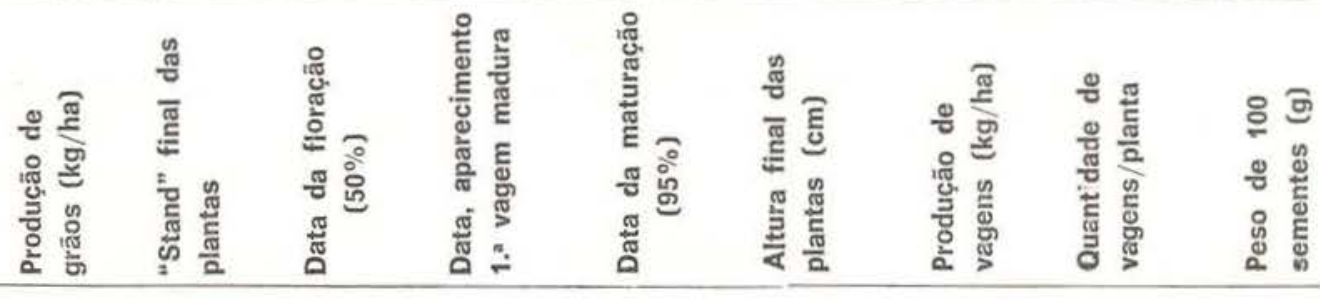

\begin{tabular}{|c|c|c|c|c|c|c|c|c|c|}
\hline $\begin{array}{l}\text { Produção de grãos } \\
\text { (kg/ha) }\end{array}$ & 1 & 0,22 & 0,11 & 0.12 & $0.31+$ & $-0,01$ & $0.60++$ & 0,20 & 0.17 \\
\hline $\begin{array}{l}\text { "Stand" final das } \\
\text { plantas }\end{array}$ & 0,22 & 1 & 0,04 & 0,17 & $-0,16$ & 0,14 & 0,20 & $-0.28+$ & 025 \\
\hline $\begin{array}{l}\text { Data da floração } \\
\qquad(50 \%)\end{array}$ & 0,11 & 0,14 & 1 & $0,69++$ & 0,21 & $0.48++$ & $0,40++$ & 0.22 & 0,10 \\
\hline $\begin{array}{l}\text { Data, aparecimentr } \\
\text { da } 1 .{ }^{\text {. }} \text { vagem madura }\end{array}$ & 0,12 & 0,17 & 0.69 & 1 & 0,70 & 0,64 & $0,37++-$ & -0.05 & 0,17 \\
\hline $\begin{array}{l}\text { Data da maturaçăo } \\
\qquad(95 \%)\end{array}$ & $0,31+$ & $-0,16$ & 0,21 & $0,70++$ & 1 & $0,58++$ & $0,39++$ & 0,15 & $0,32+$ \\
\hline $\begin{array}{l}\text { Altura final das } \\
\text { plantas }(\mathrm{cm})\end{array}$ & $-0,02$ & 0,18 & $0,48++$ & $0.64++$ & $0.58++$ & 1 & 0,18 & $-0,21$ & $0.42+-$ \\
\hline $\begin{array}{l}\text { Produção de vagens } \\
\text { (kg/ha) }\end{array}$ & $0,60++$ & 0,20 & $0,40++$ & $0,37++$ & $0,39++$ & 0,18 & 1 & $0,36++$ & 0,07 \\
\hline $\begin{array}{l}\text { Quantidade de } \\
\text { vagens por planta }\end{array}$ & 0,20 & $-0,28+$ & 0,22 & $-0,05$ & 0,15 & $-0,21$ & $0,36++$ & 1 & $0,51++$ \\
\hline $\begin{array}{l}\text { Peso de } 100 \\
\text { sementes }(\mathrm{g})\end{array}$ & 0,17 & 0,25 & 0.10 & 0,17 & $0.32+$ & $0,42++$ & 0,07 & $0.51++$ & 1 \\
\hline
\end{tabular}

Em várias localidades da região tropical (Quadro IV) a cultivar VITA-3 mostrou-se superior ou igual, em produtividade, à cultivar VITA-1, com exceção na Costa do Marfim.

A cultivar TVu 1502, uma das melhores na vấrzea do rio Solimões (Rahman, 1978), produziu, no presente experimento, $1310,25 \mathrm{~kg} / \mathrm{ha}$ de grãos.

O "stand" final das plantas mostrou uma cliferença significativa, sendo que esta carac. terística foi influenciada pelo ataque de lagarta rosca e lagarta elasmo na época de emergência e, posteriormente, pelo fungo causador da podridão branca da haste (Sclerotinia sclerotiorum) e rizoctoniose (Rhizoctonia spp).

A floração ocorreu entre 32 a 38 dias após a emergência enquanto que no experimento feito na várzea (Rahman, 1978) variou de 43 a 50 dias, mostrando que a alta pluviosidade pro- vocou o prolongamento também do ciclo vegetativo da cultura. A principal causa dessa diferença, foi a época de semeadura e, conseqüєntemente, houve efeito da precipitação e do fotoperiodismo, uma vez que na várzea a semeadura ocorreu no dia 29/10/1975 e, durante o ciclo vegetativo, recebeu precipitação inten sa dos meses de dezembro e janeiro, ocasionando também maior incidência de pragas e doenças. O fotoperiodismo é influenciado mais pela latitude; as cultivares tropicais não florescem muito precocemente nas regiões temperadas, já as cultivares das regiốes temperadas, quando cultivadas próximo à linha do Equador, atıngem a maturação mais precocemente do que na região de origem.

$\mathrm{O}$ aparecimento a $1^{\mathrm{a}}$ vagem madura ocor reu entre 44 a 60 dias, após a emergência, enquanto que o periodo de maturação variou de 
QUADRO IV - Resultados de produçāo đe grãos das cultivares VITA-3 e VITA-1 em Nigéria (Singh, 1976 e Raheja, 1976), em Ghana (Agyen-Sampong, 1976), $\in \mathrm{m}$ Sierra Leone (Taylor, 1976) e em Costa do Marfim (Assa, 1976).

\begin{tabular}{|c|c|c|c|}
\hline \multirow{2}{*}{\multicolumn{2}{|c|}{ Local e ano }} & \multicolumn{2}{|c|}{$\begin{array}{c}\text { Cultivar } \\
\text { (produçāo } \mathrm{kg} / \mathrm{ha} \text { ) }\end{array}$} \\
\hline & & VITA-3 & VITA-1 \\
\hline \multirow{3}{*}{ Nigéria } & Ibaaan - 1974 & 1469 & 1308 \\
\hline & Ibadan -1975 & 1045 & 527 \\
\hline & Samaru - 1975 & 2334 & 2141 \\
\hline \multirow{4}{*}{ Ghana } & Ejura - 1975 & 984 & 684 \\
\hline & Pokoase - 1975 & 1360 & 1413 \\
\hline & Nyanpala - 1975 & 220 & 234 \\
\hline & Kwadosa - 1975 & 244 & 180 \\
\hline Sierra & Njala - 1974 & 1455 & 1346 \\
\hline Leone & Njala — 1975 & 1079 & 999 \\
\hline \multirow{2}{*}{$\begin{array}{l}\text { Costa do } \\
\text { Marfim }\end{array}$} & & & \\
\hline & Abidjan - 1976 & 2062 & 3070 \\
\hline
\end{tabular}

52 a 78 dias após a emergência. Pela análise dos dados, constatou-se uma alta correlação positiva entre floração e a maturação.

A altura final das plantas variou de 30,55 a $131,97 \mathrm{~cm}$ sendo que as plantas altas em geral correlacionaram-se com alta produtividade de grãos, com exceção das cultivares TVx1193-059D e INPA-III. Houve também uma correlação positiva entre altura final das plantas contra a data de floração, aparecimento da $1^{\text {a }}$ vagem madura e maturação, mostrando que maior cicio acarreta maior crescimento da planta.

Com relação à produção de vagens (vã gens não debulhadas) não se mostrou diferença significativa entre as cultivares, sendo observada uma alta correlação positiva com a produção de grãos, ciclo da planta, altura da planta e quantidade de vagens por planta.

A quantidade de vagens por planta variou de 49,42 da cultivar TVx3-5G a 15,65 da cultivar INPA-III. Houve uma correlação negativa com a "stand" final das plantas indicando que maior número de vagens por planta correlaciona-se com a menor "stand" das plantas. Ainda se verifica que a maior produção de vagens cor relaciona-se positivamente com maior número de vagens.

A cultivar VITA-3 obteve a maior peso de 100 sementes juntamente com a cultivar INPAIII, com 21,88 e 19,42 gramas, respectivamente, e o menor peso foi o da cultivar TVx1836-409E. com 10,45 gramas.

O indice de debulha variou de $66,85 \%$ na cultivar TVx1836-409E a $26,07 \%$ na cultivar TVx33-1G (Quadro V). A correlação entre a produção de graus e a produção de vagens foi altamente positiva, mas o indice de debulha nem sempre mostra que a maior produção de vagens tem maior produção de grãos, como se verifica na cultivar TV×33-1G com $4258 \mathrm{~kg} / \mathrm{ha}$ cle vagens, tendo $1110 \mathrm{~kg} / \mathrm{ha}$ de grãos, mostrando o menor índice de debulha.

A cultivar VITA-3 obteve, em geral, o melhor desempenho das características agronômicas, tais como: índice de debulha de $61,83 \%$, alta produção de grãos, alta peso de $100 \mathrm{se}$ mentes, altura média da planta com $123 \mathrm{~cm}$, quantidade média de vagens por planta razoável e ciclo da planta médio.

QUADRO V - Indice de trilha, obtido pela equação: Produção de grãos $(\mathrm{kg} / \mathrm{ha})$

Produção de vagens $(\mathrm{kg} / \mathrm{ha})$

Cultivar Indice de trilha $(\%)$

$\begin{array}{ll}\text { TVx1836-409E } & 66.85 \\ \text { TVx1836-9E } & 62.48 \\ \text { VITA-3 } & 61,83 \\ \text { TVx1836-348E } & 61.42 \\ \text { VITA-4 } & 61,04 \\ \text { TVx66-2H } & 59,95 \\ \text { TVx456-01F } & 58.58 \\ \text { VITA-1 } & 5768 \\ \text { TVx1836-440E } & 57,54 \\ \text { TVx1193-059D } & 57,25 \\ \text { TVx1836-429E } & 56.48 \\ \text { TVu662 } & 56,30 \\ \text { TVu1502-1C } & 54,69 \\ \text { TVx2551 } & 53.67 \\ \text { TVx1836-473E } & 53.45 \\ \text { TVx3-5G } & 52.14 \\ \text { VITA-5 } & 49,50 \\ \text { TVx30-1G } & 48.59 \\ \text { INPA-III } & 44,79 \\ \text { TVx33-1G } & 26,07\end{array}$




\section{CONCLUSÕES E RECOMENDAÇÕES}

1) Todas as cultivares introduzidas foram superiores em produtividade à cultivar local, sendo que foram selecionadas as cultivares que produziram acima de $1800 \mathrm{~kg} /$ ha de grãos. como: VITA-3, TVx1193-059D, VITA-1, VITA-4 e TVx456-01F.

2) A cultivar VITA-3 obteve, em geral, o melhor desempenho das características agronômicas estudadas, tais como: índice de debulha de $62 \%$, alta produção de grãos, alto peso de 100 sementes, altura média da planta com $123 \mathrm{~cm}$, quantidade média de vagens por planta razoável e ciclo biológico da planta médio.

3) Houve melhor resultado no experimento de terra firme do que no da várzea, mas devem ser estudados tais fatos ainda em épocas e locais diferentes, visando principalmente à resistência a pragas e doenças.

\section{SUMMARY}

Twenty cultivars of cowpea (Vigna unguiculata (L.) Walp), 19 introductions (cultivars from IITA) and one local were studied as the performance in "Terra Firme" (upiand condition), during the growing season of 1977. It showed that the nineteen new entries performed better than the major local cultivar, INPA-III. The cultivars that produced the highest yields were: VITA-3, TVx1193059D, VITA-1, VITA-4 and TVx456-01F with about 2128 , 2055, 2038, 1957 and $1950 \mathrm{~kg}$ of dry seeds per hectare, respectively. The VITA-3 performed better os for as the study of agronomic caracteristics were concerned, such as: efficiency of machines of $62 \%$, high seeds yields, high seeds weight, plant height with $123 \mathrm{~cm}$, middle biological cycle and reasonable average number of pods per plant. There was little incidence of insects and diseases during the growing period, that was a consequence of low rainfall. The most damaging insect was the cucumber beetle (Diabrotica spp) some isolated plant showed cowpea mosaic virus (CPMV) and white rottenness of rod (Sclerotinia sclerotiorum). Other studies such as regional yield trial time of seeding and disease reactions, should be conducted with these new lines before making a final recomendation.

\section{REFERENCIAS BIBLIOGRÁFICAS}

ALBRECHT, H. R.

1975 - Registration of genetic stocks, VITA-1 Coupea, Vigna unguiculata (L) Waip. IITA,
Ibadan, Nigeria, - Registration of Genetic Stocks, VITA-3 Cowpea, Vigna unguiculata (L) Walp. IITA. Ibadan, Nigeria.

AGYEN-SAMPONG, $M$.

1976 - Co-ordinated minimum insecticide trial: yield performance of insect resistant cowpea cultivars from IITA compared with Ghanian cultivars. Tropical grain legume bulletin, $5: 6$, july.

ASSA, A. D.

1976 - Co-ordinated minimum insecticide trial: yield performance of insect resistant cowpea cultivars from IITA. Tropical grain legume bulletin, 5:9, july. Godfrey-SamAggrey, W.; Francis, B. J. \& Kamara, C. S.

1976 - The protein evaluation of cowpea (Vigna unguiculata) and benniseed (Sesamum indicum) from Sierra Leone. Tropical Science, $18(3): 147-54$.

RAHEJA, A. K.

1976 - Co-ordinated minimum insecticide trial: yield performance of insect resistant cowpea cultivars from IITA compared with Nigeriam cultivars. Tropical grair. legume bulletin, 5:5, july.

RAHMAN, $F$.

1978 - Produção de cultivares de feijāo da praia (Vigna unguiculata) na várzea do rio Solimōes no Caldeirāo (Cacau Pirera) no período de 1975/76. Acta Amazonica, 8(1): 13-17.

REGO, F.P.; PINTO, G.P.; OLIVEIRA FILHO, J.P.S.; JESUS, F.M.M.

1970 - Composição de Phaseolus e Vigna. Recife. Inst. de Pesq. Exp. Agrop. do Nordeste. 7p. (mimeografado).

RIBEIRO, M.N.G.

1977 - Boletim meteorológico. INPA-CNPq, Manaus.

SINCH, S.R.

1976 - Co-ordinated minimum insecticide trial: yield performance of insect resistant cowpea cultivars from IITA compared with Nigeriam cultivars. Tropical grain legume bulletin, $5: 4$, july.

TAYLOR, W.E.

1976 - Co-ordinated minimum insecticide trial: yield performance of insect resistant cowpea cultivars from IITA compared with Sierra Leone cultivars. Tropical grain le. gume bulletin, $5: 7$, july.

(Aceito para publicação em 12/05/81) 